\title{
Information Competence Structure and Content of the Higher School Students
}

\author{
Almira K. Garayeva \\ Kazan (Volga region) Federal University, 420008, Kazan, Russia \\ Email: almiragaraeva09@yandex.ru \\ Elena P. Kartashova \\ Mari State University, 424000, Yoshkar-Ola, Russia \\ Gulnaz F. Nizamutdinova \\ Kazan National Research Technological University, 420015, Kazan, Russia \\ Yuri D. Kudakov \\ Chuvash State Pedagogical University named after I.Y. Yakovlev, 428032, Cheboksary, Russia \\ Guliya N. Akhmetzyanova \\ Kazan (Volga region) Federal University, 420008, Kazan, Russia \\ Marina V. Zhuravleva \\ Aygul M. Gatiatullina \\ Kazan National Research Technological University, 420015, Kazan, Russia
}

Doi:10.5901/mjss.2015.v6n2s3p254

Abstract

For free orientation in the flow of information people should possess information competence as one of the components of professionalism. In this regard, the article reveals the structure and content of the information competence of students, including motivational and values, cognitive, activity, communicative and health saving components that are in relationships and are aimed at ensuring the integrity and continuity of the process of students' information competence forming in conditions of modern high school. The article also describes the problem of the teachers' functions' expansion involved in this process. The article can be recommended for use in modern practice of educational institutions, as well as in the system of teacher training.

Keywords: information competence, structure and content, higher school students

\section{Introduction}

\subsection{The urgency of the problem}

The dynamic development of the information society stipulates that the professional activities of modern young professional require continuous education, commitment to continuous improvement of his professional competence. In modern conditions, even in the period of training of future specialists several generations of hardware and software are changed, new information technologies are born, the content of Informatics as a science is changed and clarified. Therefore, during training, the student should not only form the subject knowledge and skills, but also to promote the development of those personal qualities that would enable in future to solve new problems (Sibgatova et al., 2015; Masalimova et al., 2014; Khairullina et al., 2015).

Therefore, among the general competencies which are necessary for professional activity of future specialists, in 
addition to personal and interpersonal competencies, we identify information competencies under which cognitive abilities are understood, i.e. the perception and use of ideas and thoughts; methodological abilities-time management, decision making, strategy choice, and so on; information and communication skills, the ability to extract, analyze, and effectively use information.

\subsection{Information competence, information culture, information literacy}

The concept of "information competence" and "information culture" are basic in information and cultural approach. K. Tyner suggests definition of "information literacy" as "the ability to find, evaluate and effectively use information in personal and professional activities" (Tyner, 1998.). A. C. Khutorsky (2002), understands informational competence the following way: using real objects (TV, tape recorder, telephone, Fax, computer, printer, modem) and information technology (audio - video, e-mail, media, Internet) skills to search, analyze and select the necessary information, to organize, convert, keep and send it are formed (Khutorsky, 2002). This competence provides future teachers' activity skills in relation to the information contained in academic subjects and educational fields, as well as in the surrounding world.

Currently, the problem of students' information competence formation is becoming increasingly important from both science and practice. To date, a large number of technologies and teaching techniques based on efficient approaches to knowledge transferring to students, his cognitive abilities' development are developed and implemented. But does this mean that the presented technologiesare able to solve the problems posed by advanced professional education: the formation of a competitive specialist, not satisfied with ready-made recipes for every occasion of life, able to find new solutions by optimal ways? Analysis of contemporary interpretations of the term "information competence" (Trishina, 2005; Zaitseva, 2002; Piyavski, 2009 and others) showed that in modern conditions the quality personal characteristic is understood as a new literacy, which includes skills of active, independent information processing by man (Zaitseva, 2002; Trishina, 2005).

\subsection{The content of the information competence}

Information competence includes the following elements:

1. Theoretical knowledge, practical skills of information technology using (IT) in professional activities.

2. Creativity in information technology application to practical tasks' solution, as well as in information processing, storage and transmission organization.

3. Flexibility of thinking, the ability to self-education and professional development in the field of information technology.

4. Formed worldview and system of personal values and life priorities (Slastenina, 2007).

Modern competitive specialist in almost any sphere of professional activity uses information technology in various fields, namely: to search for the information required in his professional field of activity; for storage of the documentation required in professional practice; for the presentation in the information space, contributing to the competitiveness of modern specialists; for implementation linkages with other actors; for participation in grant activities.

Information competencies for competitive expert means:

- skills to work with different information sources (books, textbooks, reference books, atlases, maps, encyclopedias, directories, dictionaries, CD-ROMs, Internet);

- independent search, extraction, systematization, analysis and selection of necessary information for educational problems' solution, its organization, reform, preservation and transmission;

- orienteering in information flows, and the ability to highlight the most important and necessary information;

- the ability to consciously perceive the information disseminated through media channels;

- $\quad$ proficiency in the use of information devices and information technologies;

- knowledge of various computer graphic editors for the application of these technologies in the creation of advertising texts and images that will bring the right information to the recipient in the most accessible form (CorelDraw; PowerPointu so on) (Khutorsky, 2002).

It follows from the above said that currently needs in the formation of students' information competence of higher education in terms of undergraduate dictate that a modern University should be focused more on productive teaching methods aimed at the development of the creative potential of the future specialist.

Psychological science distinguishes between two main types of intellectual works: reproductive (reproducing) and productive (creative, search).Reproductive activity is done according the sample, by order, it is reproduction, or 
identification of already known relations, it is the most economical way of acquiring knowledge, without which students, especially first year students, will not study. In the process of productive activitythe reproductive one is not excluded, but it becomes auxiliary. In the framework of productive activities the learned earlier algorithm allows to find new knowledgein non-standard situations, to build up new rules of action and individual learning algorithm. While the students look for ways of mental actions independently.

If the student in terms of bachelor degree who is going to work with public relations, based on his own experience in research activity independently "produces" knowledge in the learning process, and does not only receive them ready, he will tend to act similarly in his future careers. In the formation of information competence a conscious learning more clearly identification of characteristics of the basic concepts, the expansion of knowledge, the formation of different abilities and skills, ensuring continuity with other disciplines are taken place.

\section{Literature Review}

Analysis of research approaches to the content disclosure of the term "information competence" shows that this problem is being studied by many scientists (Bershadsky, 2006; Golovko, 2006; Bokareva, 2003; Zavialov, 2005; Zakharova, 2003; Nass, 2009; Kleynosova, 2009; Gulyakin, 2010; Zeer, 2000; Filatova, 2005; Ivonin, 1999; Karakozov, 2000; Bespalov, 2003 and .etc.), who believe that we should not consider information competence as a set of strictly defined quality characteristics because of different specialties varies it in the course of professional training and professional work according the content and volume of special knowledge.

Revealing the essence of the concept "information competence of students", A. A. Mukasheva (2009), includes an individual's ability to apply specialized knowledge and skills in the field of computer and information technologies to solve professional tasks, for professional self-development and self-improvement (Mukasheva, 2009). Accordingly, it is possible to define the following structural components of this competence: cognitive, activity, creative, axiological, the content of which is determined by the complexity of the professional functions of a specialist, increasing of his role in the development of production in the conditions of information society.

Additionally, there is need of differentiation of the educational process, the split of personal qualities. On this basis, Y. A. Plotonenko (2009), identifies the following structural and content components of information competency:

- cognitive-content component, characterized by students' holistic knowledge about the information environment, providing the experience of information activity and orientation in the environment, awareness of the objectives and their capabilities in the implementation of information activities, defining the system of specific practical skills of working with information, the optimal use of information systems and technologies, their development and support in multilateral professional activities, selection and accumulation of the necessary information about the possibilities of information technology in meeting the educational and cultural needs;

- socio-communicative component, which includes the principles and rules of behavior in information and communication systems in terms of human interaction with computer and information environment that involves students' abilities in a flexible and constructive dialogues makingas "person - person", "human computer", "human - computer - human" and understanding of ethical, moral, and aesthetic standards prevailing in these relationships;

- value-motivational component, which is a system that combines students' position and setting, valuable attitude to the objects and phenomena of rapidly changing information environment, an adequate representation of the global information space, information interaction in it, the opportunities and challenges in human understanding; it is associated with students' knowledge about the value priority of human life, health, and spiritual development of the individual;role of information technology in the development of modern civilization; legal, ethical and moral standards of work in the information environment; information security of society and the individual, about the advantages and disadvantages, diagnosis and prognosis of society and humanlife informatization process (Plotonenko, 2009).

In many contemporary studies the students' information competence formation is seen as a strategic factor in their preparation for future careers, providing the ability to navigate in conditions of a constant information volume increase used to solve professional problems and in lifelong learning. Besides, there are value-motivational, cognitive, technological, reflexive components of students' information competence.

Accordingly, the structure of students' information-communicative competence N.B. Strekalova (2009), defines as the aggregate of the following components, which can also be referred to specialists in public relations:

- information retrieval component, indicating the information seeking technologies possession in electronic 
networks of different types and work principles possessionin hypertext systems, information placement technologies possession in the global network;

- information management component, showing the development of electronic control and management technology of material and human resources, implementation of electronic document management and use of legal-reference systems;

- communication component, reflecting the willingness to use information transmission technologies via electronic networks and non-verbal communication, principles of electronic mail;

- text and visual components, indicating the possession of technologies for the creation and processing of electronic texts of various styles, electronic presentations and hypertext;

- hardware-system component, reflecting the willingness to use hardware-technical base of information and communication technologies and knowledge of the basic principles of storing, collecting and displaying information (Strekalova, 2009).

\section{Results and Discussions}

\subsection{The components of students' information competence formation}

Taking into account the proposed points of view in psychological and pedagogical literature on the component composition of information competence formation, it is recommended to allocate motivationally-axiological, cognitive, activity, communicative and health-preserving components of information competence formation of future specialists in public relations, and to consider them from the perspective of client-oriented environment.

\subsubsection{Motivational-value component}

Motivational-value component of students' information competence formation includes motives, values, feelings and emotions caused by the interaction of the selected components and creating favorable learning and educating the clientoriented environment. The selection of this component facilitates consideration of the real interests and needs of not only students, but also future customers, their advertised services and products and increase their motivation to information activities through the creation of natural wishto communicate with the client, their value orientations and emotionalevaluative attitude to the learned content of education, as well as independence and activity, both in educational and in extra-curricular process.

\subsubsection{The cognitive component}

This componentprovides mastering the knowledge body about information activity, its peculiarities and regularities. This component works on the implementation of the content and information functions, contributes to the information functioning in the students' minds about the basic facts, concepts, revealing the essence of information competence. The content of the cognitive component includes information knowledge based on interdisciplinary, integration of the Humanities, Sciences and professional components, deep inner science of the unity of all disciplines, allowing to assess the customers' capabilities, needs and preferences;

\subsubsection{Activity component}

Activity component involves the ability to apply knowledge in information activities, namely the ability to use modern information technologies and networks for effective communication, including foreign students, skills of self-presentation in the information space, participation in grant activities focused on the needs and preferences of customers;

\subsubsection{Communicative component}

This component is characterized by the skill and ability of students to apply information knowledge and methods of cooperation in the information space. 


\subsubsection{Health saving component}

Health saving component aims at preserving and strengthening the health of future specialists in the course of their professional activities related to information technology, which includes knowledge about irregularities in their health that may have an impact their future and their timely correction.

\subsection{Functions of information competence of a higher school teacher}

As functions of information competence of a teacher demonstrating actual client-customer relations, the following are presented:

- informational, requiring modernization of the content of teachers' training, orientation on information activities;

- epistemological (cognitive), namely, showing that the teacher in the process of information activities systematizes information knowledge about products, services and potential and actual clients in the process of information resources use in professional activity;

- communicational, manifested in the semantic component, which is expressed on paper and electronic media;

- constructive, involving the teachers' information activity planning and design on the material of the taught subject;

- integrative, namely showing, that the student's person is affected by many factors contributing to the manifestation of his individual properties which are adequate to the objectives of this educational process;

- organizational function, implemented on the basis of the teachers' skills to choose the optimal ways of information activities organizing;

- educational function, including professionally-active component - the work with information (knowledge of different sources, forms and methods of work with information, retrieval information systems knowledge, the skills of analysis, synthesis and generalization of information, the ability to present information, the ability to choose the optimal solution), as well as reflexive and communicative component - the creative application of information (the ability to self-control, communication and joint activities, professional information correction, awareness and critical analysis of information activities, creative projects making).

In his research S. Mochenov (2007), notes that the promotion of information technologies in the University requires hard work on the implementation of various projects and organizational procedures related to the integration of information technology with the curricula, computer equipment installing, acquisition and development of special software training, teaching and engineering personnel training, the development of telecommunication systems.

From the above it follows that the Informatization of the University means a new approach to the education quality provision problem, efficiency of scientific activity, requiring changes in the nature of the educational process aimed at developing greater independence of students in educational curricula mastering, disclosure of their capacity in the process of skills acquiring to work with modern software and information resources, including a focus on taking into account the conditions of the client-customer interaction.

\section{Conclusion}

Thus, in the course of the study, we can conclude that the above-mentioned components of high school students' information competence formation (motivationally-axiological, cognitive, activity, communication, health-preserving) are interrelated, and the absence of one of them destroy the integrity and continuity of the process. However, not all students have the same opportunities that allow them to be genuine entity of information activity. The need for specialists training with information competence puts forward new requirements to modern teacher, whose tasks are expanding and include informational, cognitive, communicative, constructive, integrative, organizational and development functions.

On the basis of research-based findings, we can identify the following organizational-pedagogical conditions of effective students' information competence formation:organization of information-educational environment by enriching the information resources; diagnosis and subsequent monitoring of educational needs, motivations and level of students' knowledge; inclusion of students to educational activities using remote sensing technology; stimulating of independent learning and cognitive activity of students on the basis of information and communication technologies using.

The study does not reveal the fullness of the possibilities of students' information competence forming, and is one of the variants to problem solutions. In the course of work separate components of its formation were defined, which can be used in further pedagogical research on the development of students' information competence. The article can be recommended for use in modern practice of educational institutions, as well as in the system of teachers' training. 


\section{References}

Bershadsky, M. E. (2006). Scientific method in pedagogy. Educational technology: 4, 8.

Bespalov, P. V. (2003). Computer competence in the context of personality-oriented training. Pedagogy: 4, $41-45$.

Bokareva, G. A., \& Shmelev, S.V. (2003). Information and communication readiness specialist. School technology: 2, 106-111.

Filatova L. O. (2005). Competence approach to the construction of learning content as a factor of continuity of school and higher education. Additional education: 7, 9-11.

Golovko, T. G. (2006). Development of information competence of the teacher in the process of training. Rostov-on-Don, 27.

Gulyakin, D V. (2010). Distance Learning as a factor of social - information competence of the future expert. Open and distance education: 2, 19 - 24.

Hutorskiy, A.V. (2005, December 12). Technology and design of key subject specific competences. In internet Journal "Eidos". Retrieved December 12, 2005, from http://www.eidos.ru/journal/2005/1212.htm

Ivonin, A. O. (1999). The role of information resources in improving the performance of teaching services of the education system. Ural State University, 38-41.

Ivonin, A. O. New information technologies in education. http://www.usu.ru/frames/win/usu/events/1998/seminarlT/market.html.

Karakozov, S. D. (2000). Information culture in the context of the general theory of culture identity. Educational Informatics: 2, 41-55.

Karakozov, S. D. (2005). The development objective of teacher training in the context of computer science education informatization. Moscow, 51.

Khairullina E. R., Valeyev A. S., Valeyeva G. K., Valeyeva N. S., Leifa A. V., Burdukovskaya E. A., Shaidullina A.R. (2015). Features of the Programs Applied Bachelor Degree in Secondary and Higher Vocational Education. Asian Social Science; Vol. 11, No. 3, 213-217, doi:10.5539/ass.v11n4p213.

Khutorsky, A. V. (2002). Key competencies and educational standards. Branch of philosophy of education and theoretical pedagogy RAO Center "Eidos", from http // www.eidos.ru / news / compet.htm

Kleynosova, N. P. (2009). Formation of information competence in teaching computer science and information technology on the basis of the activity approach. Computer science and education: 1, 127-128.

Masalimova, A.R., Schepkina N.K., Leifa A.V., Burdukovskaya E.A., Shaidullina A.R. (2014). Mentoring perfection in modern enterprises conditions: practical recommendations. American Journal of Applied Sciences, 11, 1152-1156, DOI: 10.3844/ajassp.2014.1152. 1156.

Mochenov, S. (2007). Informatization - the key to improving the quality of training. Higher Education in Russia: 2, 94-98.

Mukasheva, A. A. (2009). Formation of computer-information competence of students of high school in the training (Unpublished master's thesis). Chelyabinsk, 175.

Nass, O. V. (2009). A model of competence of teachers in the creation of computer tools. Education today: 8, 60-62.

Piyavski, S. A. (2009). Informatization and Competence Approach. Vestnyk: 2, 24-29.

Plotonenko, Y. A. (2009). Student-centered approach in the formation of information competence of students of high school. Tyumen, 27.

Sibgatova K.I., Mirzagalyamova Z.N., Pupysheva E.L., Mirzanagimova F.I., Shkinderova I.N., Nuriyeva E.N., Masalimova A.R. \& Schepkina N.K. (2015). The Educational Institution Teachers and Professional Community Representatives' Readiness Formation for the Joint Pupils' Career Guidance Implementation. Review of European Studies, Vol. 7, No. 1, 74-79, doi:10.5539/res.v7n1p74

Slastenina, V. A. (2007). Pedagogy Professional Education: Proc. Guide for students. Moscow: "Academy", 368.

Strekalova, N. B. (2009). Environmental approach as a factor in the formation of information and communication competence of students of humanities. Samara, 24.

Trishina, S. V. (2005, September 10). Information competence as a pedagogical category. In internet Journal "Eidos". Retrieved September 10, 2005, from http://www.eidos.ruljournal/2005/0910-11.htm

Tyner, K. (1998). Literacy in Digital World Mahwah. London.

Zaitseva, O. B. (2002). Formation of information competence of the future teachers by means of innovative technologies. Bryansk, 19.

Zakharova, I. G. (2003). Information Technologies in Education. Moscow: Publishing Center "Academy", 192.

Zavialov, A. N. (2005). Formation of information competence of students in the computer field. Tyumen , 24.

Zeer, E. F. (2000). Key qualifications and competence in individually oriented professional education. Education and Science: 3(5), 1321. 